\title{
The prognostic value of the stem-like group in colorectal cancer using a panel of immunohistochemistry markers
}

\author{
Chee Wee Ong ${ }^{1}$, Pei Yi Chong ${ }^{2}$, Darragh G. McArt' ${ }^{1}$, Jason Yongsheng Chan ${ }^{8}$, \\ Hwee Tong Tan ${ }^{6}$, Alan Prem Kumar ${ }^{2,3,4,5}$, Maxey C. M. Chung ${ }^{6}$, Marie-Véronique \\ Clément $^{6,7}$, Richie Soong ${ }^{2}$, Sandra Van Schaeybroeck ${ }^{1}$, David J. J. Waugh ${ }^{1}$, \\ Patrick G. Johnston ${ }^{1}$, Philip D. Dunne ${ }^{1, *}$, Manuel Salto-Tellez ${ }^{1, *}$ \\ ${ }^{1}$ Centre for Cancer Research and Cell Biology, Queen's University Belfast, Northern Ireland \\ ${ }^{2}$ Cancer Science Institute of Singapore, National University of Singapore, Singapore \\ ${ }^{3}$ Department of Pharmacology, Yong Loo Lin School of Medicine, National University of Singapore, Singapore \\ ${ }^{4}$ Curtin Health Innovation Research Institute, Biosciences Research Precinct, School of Biomedical Sciences, Faculty of \\ Health Sciences, Curtin University, Western Australia, Australia \\ ${ }^{5}$ Department of Biological Sciences, University of North Texas, Denton, Texas, United States of America \\ ${ }^{6}$ Department of Biochemistry, Yong Loo Lin School of Medicine, National University of Singapore, Singapore \\ ${ }^{7}$ National University of Singapore Graduate School for Integrative Sciences and Engineering, National University of Singapore, \\ Singapore \\ ${ }^{8}$ Department of Medical Oncology, National Cancer Centre Singapore, Singapore \\ *These authors have contributed equally to this work \\ Correspondence to: \\ Manuel Salto-Tellez, e-mail: m.salto-tellez@qub.ac.uk \\ Keywords: colorectal, carcinoma, biomarkers, cancer stem-cell, immunohistochemistry \\ Received: January 22, 2015 \\ Accepted: March 07, 2015 \\ Published: March 26, 2015
}

\section{ABSTRACT}

Colorectal cancer (CRC) is the second leading cause of cancer-related deaths in the Western world. It is becoming increasingly clear that CRC is a diverse disease, as exemplified by the identification of subgroups of CRC tumours that are driven by distinct biology. Recently, a number of studies have begun to define panels of diagnostically relevant markers to align patients into individual subgroups in an attempt to give information on prognosis and treatment response. We examined the immunohistochemical expression profile of 18 markers, each representing a putative role in cancer development, in $\mathbf{4 9 3}$ primary colorectal carcinomas using tissue microarrays. Through unsupervised clustering in stage II cancers, we identified two cluster groups that are broadly defined by inflammatory or immune-related factors (CD3, CD8, COX-2 and FOXP3) and stem-like factors (CD44, LGR5, SOX2, OCT4). The expression of the stem-like group markers was associated with a significantly worse prognosis compared to cases with lower expression. In addition, patients classified in the stem-like subgroup displayed a trend towards a benefit from adjuvant treatment. The biologically relevant and poor prognostic stem-like group could also be identified in early stage I cancers, suggesting a potential opportunity for the identification of aggressive tumors at a very early stage of the disease.

\section{INTRODUCTION}

To date, the strongest prognostic value is derived from the tumor node metastasis system of staging (TNM). Patients with stage I disease have the best prognosis, with over $90 \%$ surviving past five years. These survival rates decrease to less than $5 \%$ for patients with advanced stage IV disease. The heterogeneity of colorectal cancers (CRC) at both the molecular level and in terms of prognosis is apparent; even within each stage, as there exist groups of patients with variation in both overall survival and response 
to either standard of targeted treatment strategies. The addition of clinicopathological markers such as tumor grade, invasion of lymph nodes, blood vessels or perineural invasion can further be used to identify poor prognostic subgroups of patients within each stage, but no definitive molecular signature has yet been attributed to these subgroups.

The development of meaningful subgrouping based on gene expression data, which related to prognosis, was first pioneered in breast cancer by two landmark papers in 2000 and 2001 [1, 2]. These paradigm-shifting publications emphasized how tumor specific gene expression data, through the use of high throughput microarray technology, could be used to classify patients based on the biology underlying their disease. In the last decade a number of studies have been published outlining prognostic gene signatures in colorectal cancer using various high throughput microarray platforms [3-5]. However, as these prognostic signatures were purely generated for their prognostic value they failed to address the driving biology behind each individual cancer or to relate that to potential treatment strategies. Given the extreme variation in prognosis, particularly in early stage colorectal cancer, these signatures were initially aimed at informing clinical decision around whether adjuvant treatment following surgery would provide any benefit over watchful surveillance. Nevertheless, the publication of three recent studies sought to set a new paradigm for the classification of colorectal cancer based on gene expression profiling [6-8]. While each of these studies generated independent transcriptional signatures, a common theme was the emergence of a stem cell subtype; which defined the poor prognostic group in stage II CRC. The importance of the prognostic value of this stem cell subtype was subsequently validated in the CRC consensus analysis presented at the American Society of Clinical Oncology (ASCO) meeting in 2014 [9].

Another notable characteristic of these studies were that apart from defining the biology driving disease progression, they also attempted to develop clinically useful IHC panels to assign patients to each subtype. To date, these IHC panels have yet to be fully defined or validated in retrospective cohorts or prospective trial setting. Hence, in this study, we analyze a wellcharacterized retrospective CRC cohort in order to test the prognostic value of the stem-like and inflammatory subtypes, using unsupervised clustering in relation to overall survival. This was initially examined in stage II cancers, followed by the other cancer stages. Moreover, our findings are further tested by patient stratification into either in treated and untreated groups, with the aim of validating the prognostic value of the identified subgroups in CRC using routine standard IHC methods.

\section{RESULTS}

\section{Unsupervised hierarchical clustering of stage II CRC}

Consensus unsupervised analysis of the immunohistochemistry scoring revealed proteins with co-expression patterns that grouped into two distinct clusters and one heterogeneous cluster (Figure 1b). Expression cluster 1 contained predominately markers associated with stem-like characteristics; CD44, LGR5, SOX2 and OCT4, while cluster 2 contained inflammatory and immune associated markers; CD8, CD3, COX2 and FOXP3. Cluster 3 was a more heterogeneous group containing markers associated with a wider range of characteristics. Given the clear biology emerging at this stage, we focused on the identified distinct clusters 1 and 2 . Expression of either a high stem-like or inflammatory pattern was not mutually exclusive and resulted in the appearance of four clearly distinct patient clusters. Using these clusters, we categorized the patients into one of four molecular sub-types (MST1-4) based on their expression pattern of either the stem-like markers or the inflammatory markers. These subtypes were MST1; high stem-like/low inflammatory, MST2; high stem-like/high inflammatory, MST3; low stem-like/high inflammatory, MST4; low stem-like/low inflammatory (Figure 1).

\section{Prognostic relevance of identified molecular sub-types in stage II CRC}

To investigate the clinical relevance of our identified subtypes, we carried out survival analysis using overall survival limited to five years in our stage II cohort. While there was no significant difference in survival between MST1 to 4 (Supplementary Figure S1), there appeared to be a trend towards a worse prognosis in MST1 and MST2, which both shared high expression of stem-like markers, compared to MST3 and MST4. We then re-classified the patients into high or low groups for either stem-like or inflammatory markers for survival analysis. A significantly worse prognosis was found in patients categorized in the high stem-like group compared to those with lower expression (Supplementary Table S1, $p=0.0288$ ). The separation of patients using this stem-like classifier (Figure $2 b$ ) resulted in a group with a hazard ratio (HR) of 2.150 (CI $1.083-4.271$ ). In contrast, overall survival was unaffected by classification using the inflammatory panel of markers.

\section{Effect of adjuvant treatment on prognosis of identified subgroups in stage II CRC}

Within our stage II cohort, we have patients who were either treated with adjuvant chemotherapy 


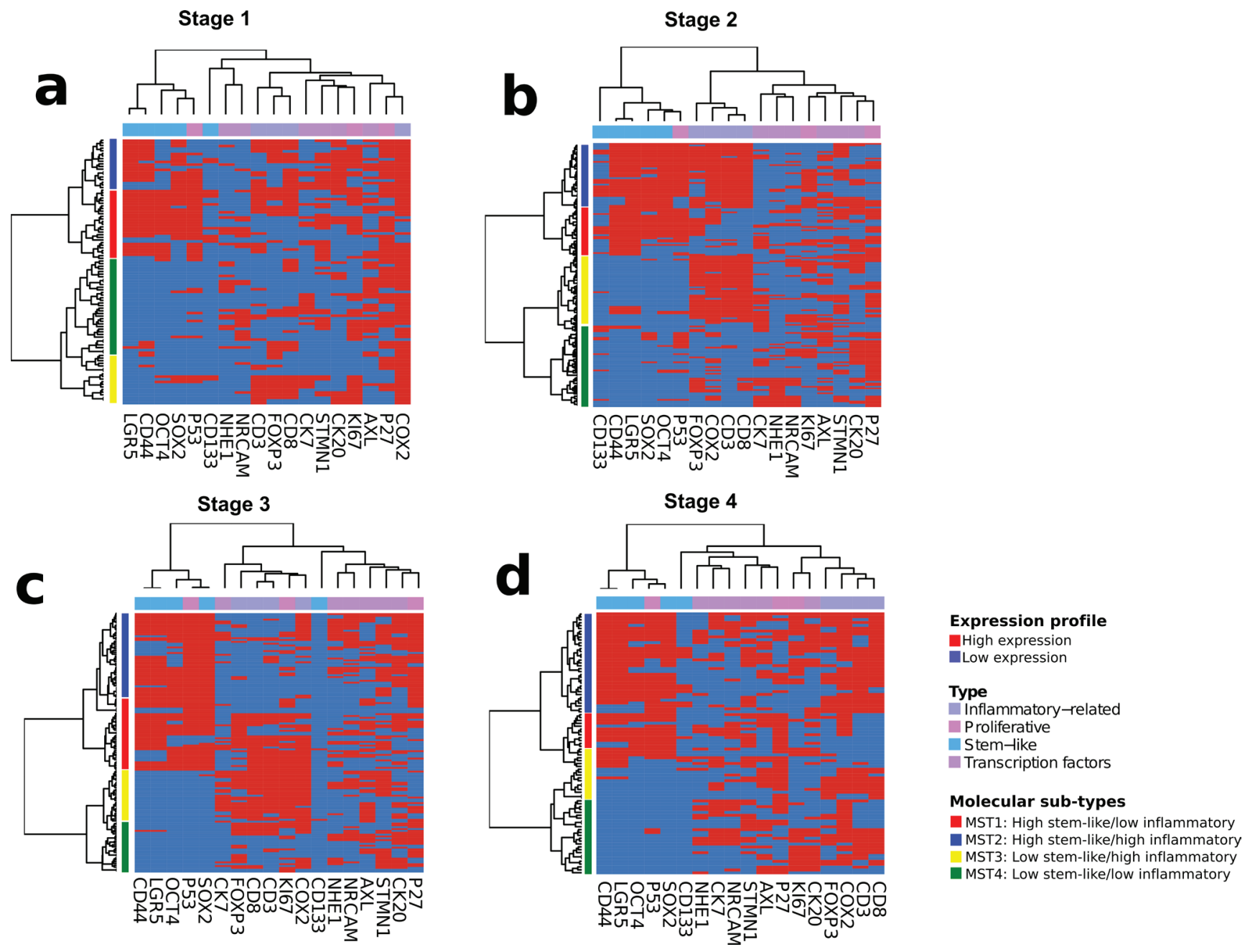

Figure 1: Unsupervised hierarchical clustering analysis of immunohistochemical staining profile. Heatmaps showing appearance of distinct patients clusters in Stage I a. II b. III c. and IV d. colorectal cancer cases.

$(30 \%)$ or untreated $(70 \%)$. Although the treatment was heterogeneous, it was predominantly fluorouracil based (5FU). Analysis of the patients who received no adjuvant treatment confirmed the true prognostic value of the stem-like classifier (Figure 2c), with an increased HR of 2.345 (CI $1.036-5.311 ; p=0.0409$ ) in the highstem patients compared to the low-stem sub-group. More importantly, analysis of the stem-like classifier in the treated-only group failed to show any prognostic value to the classifier (Supplementary Figure S2), suggesting that treatment of patients in the poor prognostic high stem-like group might improve their overall survival.

To further test this hypothesis, patients displaying a high stem-like classification appeared to show a trend towards a benefit from treatment with adjuvant chemotherapy as highlighted by an improved overall prognosis in the treated group compared to the untreated group, although this finding was not significant (Supplementary Figure S3).

\section{Identification of stem-like and inflammatory associated subgroups in later stage CRC}

Following identification of molecular subtypes in early stage patients, we carried out a similar unsupervised clustering of stage III and stage IV patients in our cohort using the same classifiers for both stem-like and inflammatory markers (Figure 1c and 1d). This approach revealed the presence of all four of our stage II molecular subtypes, in each of the later stages, alongside the individual stem-like or inflammatory groups. Although the presence of both the stem-like and the inflammatory 
a

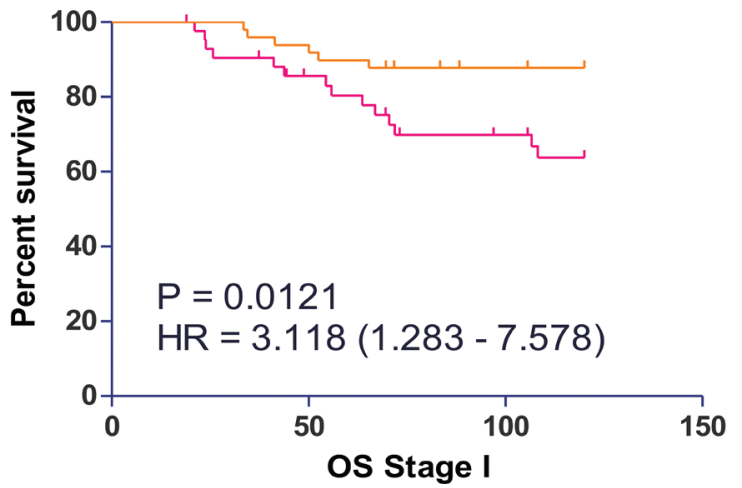

- High Stem $(n=43)$

- Low Stem $(n=49)$

OS Stage I

b

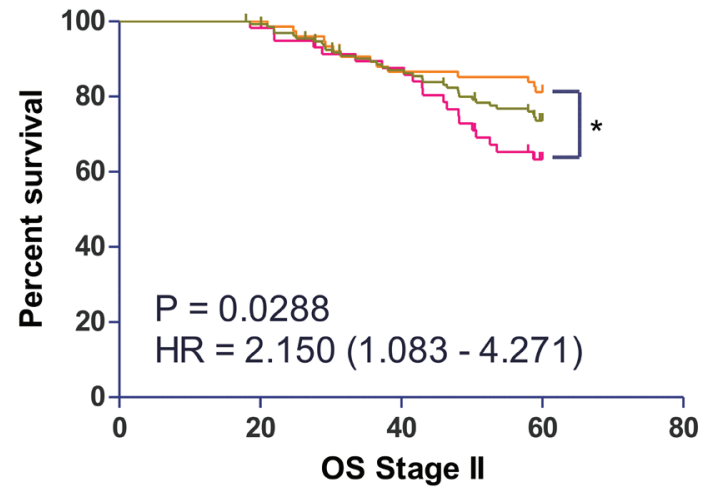

- High Stem $(n=60)$

- Low Stem $(n=75)$

+ All Stage II $(n=135)$

OS Stage II
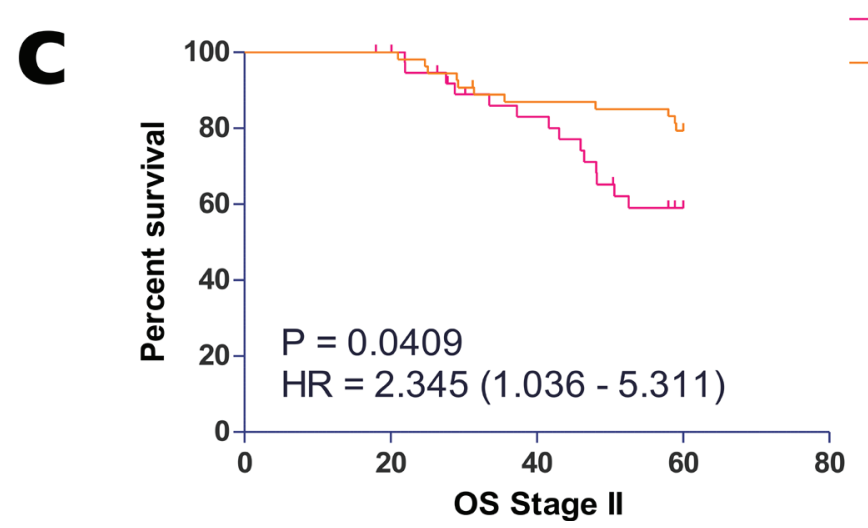

High Stem - Untreated $(n=39)$

Low Stem - Untreated $(n=54)$

Figure 2: Prognostic value of identified stem-like molecular sub-groups in a. Stage I and b. II colorectal cancer patients. The prognostic value of the stem-like classifier was also observed in c. Stage II patients who received no adjuvant treatment.

groups could be identified in stage III and IV patients in our cohort, there was no prognostic value to our classifier in these advanced stage cases.

\section{Prognostic value of the stem-like classifier in pre-invasive stage I colorectal patients}

Next, we sought to examine whether the stemlike group, which has prognostic effect in stage II, may also identify patients with poor outcome in the pre-invasive early disease population. We performed survival analysis comparing the stem-high against the stem-low group in the stage I cases. As these patients have a relatively good prognosis compared to stage II patients we used a 10-year follow up for this analysis (Figure 2a). We observed a significantly worse overall prognosis for patients classified in the stem-high group with an increased risk of death over 3 times that of the low-stem group (HR $=3.118$, CI $1.283-7.578$, $p=0.0121)$. 


\section{DISCUSSION}

Even though numerous studies have consistently showed evidence of different subtypes outlining the heterogeneity nature of colorectal cancer $[6,10,11]$, the integration of these gene expression profiles in the clinical context still require extensive validation. Using our well-characterized retrospective cohort of patients with extensive survival follow-up, we aimed to define markers of clinically relevant and diagnostically useful subgroups in colorectal cancer. As with a number of other studies, we initially focused on the stage II patients within our cohort. Using unsupervised consensus-based clustering, we found that our dataset subdivided into three general clusters based on their IHC profiles (Figure 1, Supplementary Tables S2). Although one of these clusters represented biology which was heterogeneous in nature, it was interesting that the other two clusters were underpinned by clearly distinct driving biology, namely, a subgroup showing high expression of inflammatory-related factors (CD3, CD8, COX-2 and FOXP3) and a subgroup showing high expression of stem-like factors (CD44, LGR5, SOX2 and OCT4). The identification of these two biologically diverse inflammatory-related and stem-like clusters have been reported in a number of other studies through transcriptional profiling of colorectal cancer [6].

The high expression of the inflammatory-related factors CD3, CD8 and FOXP3 has been shown in a number of other studies [12-14]. FOXP3 has been reviewed to be associated with either good or neutral prognostic effect in colorectal cancer [12]. Thus, it has been suggested that the favorable prognostic effect of FOXP3 may be due to the ability to suppress tumorpromoting inflammatory responses to gut microbes [13]. It has been hypothesized that increased inflammation could either provide a favorable environment for the dissemination of tumor cells or an indication of protective host responses [14]. The improved survival associated with CD3 and CD8 expression could be an effect of micrometastatic suppression induced by a systemic immunosurveillance mechanism [15]. The role of COX2 in the immune tumor microenvironment in colon cancer is well-defined and the uses of inhibitors, such as aspirin, in prevention of hereditary cancers of the colon are commonly accepted $[16,17]$.

In normal tissue homeostasis, the regulation of cellular renewal is carefully maintained by stem-cells and progenitor cells. The loss of this mechanism may be the underlying cause of deregulated cell proliferation leading to cancer development [18]. Both CD44 and LGR5 are widely recognized as key regulators of the stem cell phenotype, particularly in colorectal cancer [19, 20]. While the transcription factors SOX2 and OCT4 are increasingly reported to contribute to cancer progression through their functional control of cell self-renewal and the pluripotent state [21, 22]. Although both CD133 and p53 appeared to cluster within the stem-like subgroup, we chose to leave these factors out of further analysis. This was due to the overall low levels of staining observed for CD133 within our TMA (Table 2) and the current uncertainty about using p53 staining as a surrogate for mutation identification. Although given the role for both CD133 and p53 in cell self-renewal these finding do justify further investigations into the relationship of these markers within a stem-like signature.

Our finding, which shows that stem-like phenotype is associated with worse overall survival in early stage colorectal cancer, is very similar to the findings of a number of independently published transcriptional based classification studies [8-10]. While these other studies have proposed IHC markers to define their identified subtypes, using our retrospective cohort, we have shown that our panel of CD44, LGR5, SOX2 and OCT4 can similarly identify this poor prognostic subgroup. We see a clear prognostic value of our stem-like classifier in the overall stage II population (Figure 2b) and more so in the untreated patients, where the true prognostic value can be identified (Figure 2c). It is interesting however, that when patients in the adjuvant treated group are analyzed, the stem-like classifier is no longer prognostic (Supplementary Figure S2). Further analysis revealed that there was a clear trend for improved survival in the high stem-like subgroup following the addition of adjuvant treatment, although this effect was not significant, while there was no trend for improved survival in the low-stem group (Supplementary Figure S3). This trend towards a benefit from treatment in the otherwise poor prognostic group displays similarities to the study by Sadanandam et al., where they found no association between their stem-like subtype and DFS in patients receiving adjuvant therapy. Similar to the data presented here, when the untreated patients were selected individually the stem-like group was found to have a significant association with lower survival (Figure 2c). Given that a large proportion of stage II patients who are given adjuvant therapy do not gain any benefit from this treatment, this finding warrants further investigation, as current decisions on whether to offer adjuvant chemotherapy still rely on a number of other classical prognostic factors.

Although stage I patients currently have a very favorable outcome, with a 5-year survival rate of over $90 \%$, we found that the stem-like IHC panel could identify a subgroup with a poor overall survival rate (Figure 2a). Currently the proportion of patients diagnosed at stage I is low, approximately $9 \%$ in the UK, but given the recent expansion of colorectal cancer screening programs in the UK and worldwide, patients identified at this early stage will no doubt increase from its current rate [23]. Having a routine method of testing the projected increased numbers of early stage cases for traits associated with 
disease progression represents an opportunity for early intervention. Evidence for the existence of transcription profiles similar to those observed in poor prognostic groups of established colorectal cancer have been found in early serrated adenoma lesions, with suggestions that the driving biology found in the stem-like tumors may already be established in precursor lesions [7]. This latter point highlights a need for the expansion of similar studies to archived polyp collections for further investigation.

In summary, our results clearly reflect the molecular heterogeneity of colorectal cancer and are in agreement with observations in gene expression profiling studies $[6,10,11]$. Our findings also address the relevance of inflammatory and stem-like molecular subgroups in colorectal cancer. More importantly, the difference in the survival outcome between the different subtypes suggest that colorectal cancer management could be potentially improved by the inclusion of biomarker information $[24,25]$. In addition the poor-prognostic stem-like subgroup identified in this cohort appears to show a trend for improved survival rates following adjuvant chemotherapy, which may aid in selecting patients who will derive benefit from treatment. The results from our study may help shed some light on identifying this particular subtype for targeted clinical intervention, particularly at the very early stage, where there is only a small subgroup of patients who will derive any benefit from the addition of adjuvant chemotherapy following surgery.

\section{MATERIALS AND METHODS}

\section{Patient cohort and selection of immunohistochemical markers}

The patient cohort in this study comprises of 493 CRC cancer patients that underwent primary surgery for the disease from 1990 to 1999 in the National University Hospital of Singapore. For this study, formalin-fixed and paraffin-embedded tissue blocks were retrospectively collected from the Department of Pathology. Clinical and pathological data were extracted from the medical records for the purpose of the study. The procedure for this research was approved by the ethics committee of the National University of Singapore. Patient characteristics are summarized in Table 1. The information retrieved included gender, age, tumor size, tumor stage (AJCC), histological grade, vascular invasion, perineural invasion, and lymphatic invasion. Patients were staged according to the AJCC TNM classification and were monitored for relapse of disease and death. Survival time was measured from the date of diagnosis until the date of death. Patients alive after 60 months was considered censored.

For this study, a panel of 18 immunohistochemical markers were analyzed (Table 2). These markers were broadly selected and categorized by their putative role in development of colorectal cancer such as such having tumor suppressive, oncogenic, proliferative, inflammatory and stem-like properties.

\section{Tissue microarray construction and immunohistochemistry}

The details of construction of the tissue microarray has been previously described [26]. Briefly, representative areas of tumor were initially marked on hematoxylin and eosin stained slides by a pathologist. These areas were taken from the center of the colorectal tumor and were subsequently cored from the donor tissue block using a $0.6 \mathrm{~mm}$ diameter cylinder. The cylinder cores were then transplanted into a recipient paraffin block. These processes were carried out using an ATA-100 tissue arrayer (Chemicon International, Temecula, CA, USA). Three cores were taken from tissue blocks from each of the patients. A total of 10 tissue microarray blocks, arrayed in triplicates, were constructed for this study. Consecutive 5- $\mu \mathrm{m}$ sections were then placed on polylysine-coated slides for immunohistochemical analyses.

Heat-mediated antigen retrieval methods were used for all the immunohistochemical markers; these were carried out using either the MicroMED TT Microwave Processor (Milestone, Sorisole, Italy) or the Bond-Max autostainer (Leica Biosystems, Newcastle, UK). The immunohistochemistry markers used were commercially available and were validated in our previous studies (Table 2).

For the antigen-retrieval using the Microwave Processor, the sections were subjected to steaming at $120^{\circ} \mathrm{C}$ for $5 \mathrm{~min}$ in an antigen retrieval solution (10-mM citrate buffer, $\mathrm{pH}$ 6.0) (Dako, Glostrup, Denmark). To avoid non-specific targeting, they were treated with serum-free protein blocking solution (Dako, Oslo, Norway) before incubation with the marker of interest. The dilution and incubation conditions were described in Table 2. After incubation, the slides were rinsed twice in saline buffer solution before secondary antibody incubation at room temperature for an hour. For antibody detection, 3, 30-diaminobenzidine (DAB) based detection system (LSAB2; Dako, Norway) was used according to manufacturer's specifications. The stained sections were subsequently counterstained with haematoxylin.

For markers that were stained using the Bond-Max autostainer, the automated immunohistochemical staining process was carried out according to the manufacturer's protocol. Briefly, the sections were subjected to heatinduced antigen retrieval with epitope retrieval ER1 solution (Leica Biosystems) at $100^{\circ} \mathrm{C}$ for $20 \mathrm{~min}$. Subsequently, they were incubated with the primary antibody for $15 \mathrm{~min}$ and were washed subsequently with Bond washing buffer (Leica Biosystems). After washing, 
Table 1: Summary of patient characteristics $(n=493)$

\begin{tabular}{|c|c|}
\hline Clinical parameters & Number and percentage of cohort (total $n=493$ ) \\
\hline \multicolumn{2}{|l|}{ Age } \\
\hline$<65$ & $247(50 \%)$ \\
\hline$\geq 65$ & $246(50 \%)$ \\
\hline \multicolumn{2}{|l|}{ Gender } \\
\hline Male & $240(48 \%)$ \\
\hline Female & $257(52 \%)$ \\
\hline \multicolumn{2}{|l|}{ AJCC stage } \\
\hline 1 and 2 & $262(53 \%)$ \\
\hline 3 and 4 & $231(47 \%)$ \\
\hline \multicolumn{2}{|l|}{ Ethnicity } \\
\hline Chinese & $429(87 \%)$ \\
\hline Non-Chinese & $68(13 \%)$ \\
\hline \multicolumn{2}{|l|}{ Tumor site } \\
\hline Colon & $109(22 \%)$ \\
\hline Rectal & $388(78 \%)$ \\
\hline \multicolumn{2}{|l|}{ Tumor size } \\
\hline$<5 \mathrm{~cm}$ & $194(56 \%)$ \\
\hline$\geq 5 \mathrm{~cm}$ & $303(44 \%)$ \\
\hline \multicolumn{2}{|l|}{ Tumor differentiation } \\
\hline Poor & $59(12 \%)$ \\
\hline Well and moderate & $438(88 \%)$ \\
\hline \multicolumn{2}{|l|}{ Metastasis status } \\
\hline Positive & $121(25 \%)$ \\
\hline Negative & $378(75 \%)$ \\
\hline \multicolumn{2}{|l|}{ Vascular invasion } \\
\hline Present & $50(10 \%)$ \\
\hline Absent & $447(90 \%)$ \\
\hline \multicolumn{2}{|l|}{ Perineural invasion } \\
\hline Present & $41(8 \%)$ \\
\hline Absent & $456(92 \%)$ \\
\hline \multicolumn{2}{|l|}{ Lymphatic invasion } \\
\hline Present & $19(4 \%)$ \\
\hline Absent & $478(96 \%)$ \\
\hline
\end{tabular}

the slides were incubated with the secondary antibody (Bond Polymer Refine kit, Leica Biosystems) for 8 min at room temperature. Finally, chromogenic detection of the antibody was achieved by incubation with DAB for $10 \mathrm{~min}$.

\section{Analysis of immunohistochemistry}

Staining results were assessed independently by CWO and subsequently reviewed by an experienced colorectal pathologist (MST). The scorings were done 
Table 2: Summary of characteristics and expression frequency of markers, conditions used for immunohistochemistry and previous publications using the same patient cohort

\begin{tabular}{|c|c|c|c|c|c|c|}
\hline Marker & Clone & Manufacturer & Dilution & $\begin{array}{l}\text { Expression } \\
\text { frequency } \\
(N=493)^{*}\end{array}$ & Localisation & $\begin{array}{l}\text { Previous } \\
\text { publication }\end{array}$ \\
\hline AXL & HPA037422 & $\begin{array}{l}\text { Sigma Aldrich, } \\
\text { MO, USA }\end{array}$ & $1: 1000$ & $219(65 \%)$ & Cytoplasmic & $\begin{array}{l}\text { P Dunne et al., } \\
\text { Clin Can Res } \\
(2014)[27]\end{array}$ \\
\hline CD3 & LN10 & $\begin{array}{l}\text { Novocastra, } \\
\text { Newcastle, UK }\end{array}$ & 1:1000 & $246(50 \%)$ & Nuclear & Unpublished \\
\hline CD8 & $11 \mathrm{~F} 1$ & $\begin{array}{l}\text { Novocastra, } \\
\text { Newcastle, UK }\end{array}$ & $1: 40$ & $256(52 \%)$ & Nuclear & Unpublished \\
\hline CD133 & AC133 & $\begin{array}{l}\text { Miltenyi } \\
\text { Biotech, } \\
\text { CA, USA }\end{array}$ & $1: 10$ & $60(12 \%)$ & Membrane & $\begin{array}{l}\text { CW Ong et al., } \\
\text { Modern Path } \\
(2010)[26]\end{array}$ \\
\hline CD44 & SFF-304 & $\begin{array}{l}\text { Bender } \\
\text { MedSystems, } \\
\text { CA, USA }\end{array}$ & $1: 250$ & $230(47 \%)$ & Cytoplasmic & Unpublished \\
\hline CK7 & OV-TL-12/30 & $\begin{array}{l}\text { Santa Cruz, } \\
\text { CA, USA }\end{array}$ & $1: 500$ & $159(32 \%)$ & Cytoplasmic & $\begin{array}{l}\text { CW Ong et al., } \\
\text { Modern Path } \\
(2010)[26]\end{array}$ \\
\hline CK20 & KS20-8 & $\begin{array}{l}\text { Dako, } \\
\text { Denmark }\end{array}$ & $1: 500$ & $226(42 \%)$ & Cytoplasmic & $\begin{array}{l}\text { CW Ong et al., } \\
\text { Modern Path } \\
(2010)[26]\end{array}$ \\
\hline $\mathrm{COX} 2$ & M-19 & $\begin{array}{l}\text { Santa Cruz, } \\
\text { CA, USA }\end{array}$ & $1: 250$ & $351(71 \%)$ & Cytoplasmic & $\begin{array}{l}\text { CW Ong et al., } \\
\text { Modern Path } \\
(2010)[26]\end{array}$ \\
\hline FOXP3 & 236A/E7 & $\begin{array}{l}\text { Abcam, } \\
\text { MA, USA }\end{array}$ & $1: 250$ & $234(47 \%)$ & Nuclear & Unpublished \\
\hline Ki67 & SP6 & $\begin{array}{l}\text { Abcam, } \\
\text { MA, USA }\end{array}$ & $1: 200$ & $183(37 \%)$ & Nuclear & $\begin{array}{l}\text { CW Ong et al., } \\
\text { Modern Path } \\
(2010)[26]\end{array}$ \\
\hline LGR5 & EPR3065Y & $\begin{array}{l}\text { Novus } \\
\text { Biologicals, } \\
\text { CO, USA }\end{array}$ & $1: 300$ & $245(70 \%)$ & Cytoplasmic & Unpublished \\
\hline NHE1 & PRS4377 & $\begin{array}{l}\text { Sigma Aldrich, } \\
\mathrm{MO}, \mathrm{USA}\end{array}$ & $1: 100$ & $335(68 \%)$ & Membrane & Unpublished \\
\hline NRCAM & ab24344 & $\begin{array}{l}\text { Abcam, } \\
\text { MA, USA }\end{array}$ & $1: 500$ & $272(55 \%)$ & Cytoplasmic & $\begin{array}{l}\text { JY Chan et al., } \\
\text { Cancer Sci. } \\
(2011)[28]\end{array}$ \\
\hline OCT4 & H-143 & $\begin{array}{l}\text { Santa Cruz, } \\
\text { CA, USA }\end{array}$ & 1:1000 & $279(56 \%)$ & Cytoplasmic & $\begin{array}{l}\text { CW Ong et al., } \\
\text { Modern Path } \\
(2010)[26]\end{array}$ \\
\hline $\mathrm{p} 27$ & SX53G8 & $\begin{array}{l}\text { Abcam, } \\
\text { MA, USA }\end{array}$ & $1: 500$ & $299(61 \%)$ & Nuclear & $\begin{array}{l}\text { CW Ong et al., } \\
\text { Modern Path } \\
(2010)[26]\end{array}$ \\
\hline
\end{tabular}

(Continued) 


\begin{tabular}{l|l|l|l|l|l|l|}
\hline Marker & \multicolumn{2}{l}{ Mlone } \\
\hline & D-07 & $\begin{array}{l}\text { Dako, } \\
\text { Denmark }\end{array}$ & $1: 250$ & $245(49 \%)$ & Nuclear & $\begin{array}{l}\text { CW Ong et al., } \\
\text { Modern Path } \\
(2010)[26]\end{array}$ \\
\hline p53 & 57 CT23.3.4 & $\begin{array}{l}\text { Abcam, MA } \\
\text { USA }\end{array}$ & $1: 1000$ & $235(47 \%)$ & Cytoplasmic & $\begin{array}{l}\text { CW Ong et al., } \\
\text { Modern Path } \\
(2010)[26]\end{array}$ \\
\hline STMN1 & 3352 & $\begin{array}{l}\text { Cell Signaling, } \\
\text { MA, USA }\end{array}$ & $1: 250$ & $235(48 \%)$ & Cytoplasmic & $\begin{array}{l}\text { HT Tan et al., } \\
\text { J Proteome Res. } \\
(2012)[29]\end{array}$ \\
\hline
\end{tabular}

*Number of actual cases used in previous studies may differ from the total number of cases examined due to availability of clinical information, loss of cores or lack of tumor materials available for pathological scoring purposes during the time of study.
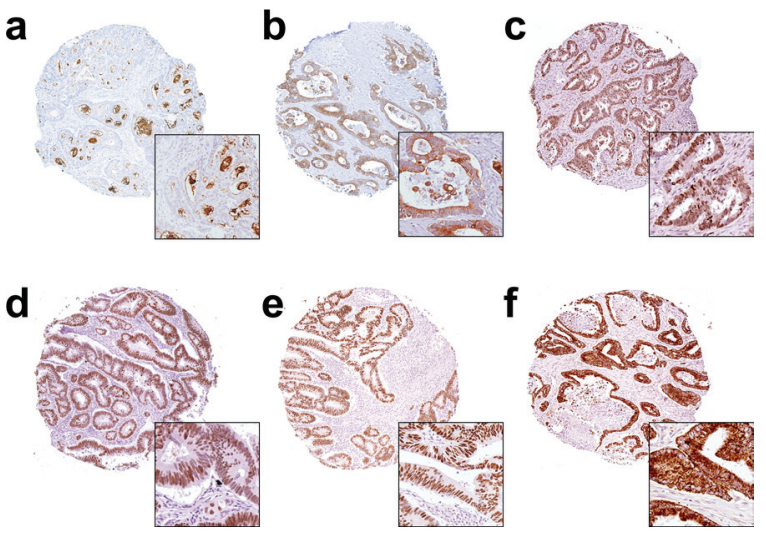

Figure 3: Representative immunohistochemistry images for the markers a. CD133, b. SOX2, c. OCT4, d. P27, e. P53 and f. COX-2.

blinded to the knowledge of patient outcomes and other clinical features. For the markers that expressed immunoreactivity in the nucleus (CD3, CD8, FOXP3, Ki67, p27 and p53), a pathological score was given semi-quantitatively as $0,+1,+2$ and +3 , corresponding to the percentage of positively stained nucleic (Figure 3 ). For the cytoplasmic and membrane expressing markers (AXL, CD133, CD44, CK7, CK20, COX2, LGR5, NHE-1, NrCAM, OCT4, SOX2 and STMN1), a fourlevel semi-quantitative classification corresponding to the staining intensity of the cytoplasmic and membrane immunoreactivity was used (Figure 3 ).

\section{Statistical analysis}

Only cases with complete information on the immunohistochemical markers were considered for analysis. Relationships between the occurrence frequencies of variables were evaluated by Fisher's exact test. To determine the prognostic value of each variable, univariate Cox proportional hazards regression was carried out. Subsequently, a multivariate Cox model was used to test for independent prognostic value. The data were summarized with hazard ratios (HR) with their 95\% confidence intervals (CI). Survival curves were plotted using GraphPad Prism Version 5. The NMF package [30] for the R statistical software [31] was used for the cluster analysis for the immunohistochemical scores. The NMF method allowed identification of clusters in an unsupervised manner based on the Euclidean distance and average linkage. All other statistical analyses were performed using the SPSS package (version 20.0 for Mac, SPSS, USA) with significance set at the 5\% level.

\section{ACKNOWLEDGMENTS}

We would also like to thank Ms Maggie Cheung Sok Lian and Ms Sandy Kim Lay Gek for their efforts in the collection of patients' clinical information and pathological materials used in this study. 


\section{FUNDING}

This study is funded by Singapore Cancer Syndicate (Agency for Science, Technology and Research, Singapore) from the following grants MN005, MN005R and MN077.

\section{CONFLICTS OF INTEREST}

The authors declare that no potential conflict of interests exists.

\section{REFERENCES}

1. Perou CM, Sørlie T, Eisen MB, van de Rijn M, Jeffrey SS, Rees CA, Pollack JR, Ross DT, Johnsen H, Akslen LA, Fluge O, Pergamenschikov A, Williams C, Zhu SX, Lønning PE, Børresen-Dale AL, Brown PO, Botstein D. Molecular portraits of human breast tumours. Nature. 2000 Aug 17;406:747-52.

2. Sørlie T, Perou CM, Tibshirani R, Aas T, Geisler S, Johnsen H, Hastie T, Eisen MB, van de Rijn M, Jeffrey SS, Thorsen T, Quist H, Matese JC, Brown PO, Botstein D, Lønning PE, Børresen-Dale AL. Gene expression patterns of breast carcinomas distinguish tumor subclasses with clinical implications. Proc Natl Acad Sci. USA. 2001 Sep 11;98:10869-74.

3. Kennedy RD, Bylesjo M, Kerr P, Davison T, Black JM, Kay EW, Holt RJ, Proutski V, Ahdesmaki M, Farztdinov V, Goffard N, Hey P, McDyer F, Mulligan K, Mussen J, O’Brien E, Oliver G, Walker SM, Mulligan JM, Wilson C, Winter A, O'Donoghue D, Mulcahy H, O'Sullivan J, Sheahan K, Hyland J, Dhir R, Bathe OF, Winqvist O, Manne U, Shanmugam C, Ramaswamy S, Leon EJ, Smith WI, McDermott U, Wilson RH, Longley D, Marshall J, Cummins R, Sargent DJ, Johnston PG, Harkin DP. Development and Independent Validation of a Prognostic Assay for Stage II Colon Cancer Using Formalin-Fixed Paraffin-Embedded Tissue. Clin Cancer Res. 2011 Dec 8;29:4620-6.

4. Wang Y, Jatkoe T, Zhang Y, Mutch MG, Talantov D, Jiang J, McLeod HL, Atkins D. Gene expression profiles and molecular markers to predict recurrence of Dukes' B colon cancer. Clin Cancer Res. 2004 May 1;22:1564-71.

5. Eschrich S, Yang I, Bloom G, Kwong KY, Boulware D, Cantor A, Coppola D, Kruhøffer M, Aaltonen L, Orntoft TF, Quackenbush J, Yeatman TJ. Molecular staging for survival prediction of colorectal cancer patients. Clin Cancer Res. 2005 May 20;23:3526-35.

6. Sadanandam A, Lyssiotis CA, Homicsko K, Collisson EA, Gibb WJ, Wullschleger S, Ostos LCG, Lannon WA, Grotzinger C, Del Rio M, Lhermitte B, Olshen AB, Wiedenmann B, Cantley LC, Gray JW, Hanahan D. A colorectal cancer classification system that associates cellular phenotype and responses to therapy. Nat Med. Nature Publishing Group. 2013 Apr 14;:1-8.

7. De Sousa E Melo F, Wang X, Jansen M, Fessler E, Trinh A, de Rooij LPMH, de Jong JH, de Boer OJ, van Leersum R, Bijlsma MF, Rodermond $\mathrm{H}$, van der Heijden M, van Noesel CJM, Tuynman JB, Dekker E, Markowetz F, Medema JP, Vermeulen L. Poor-prognosis colon cancer is defined by a molecularly distinct subtype and develops from serrated precursor lesions. Nat Med. 2013 May 19:614-8.

8. Marisa L, de Reyniès A, Duval A, Selves J, Gaub MP, Vescovo L, Etienne-Grimaldi M-C, Schiappa R, Guenot D, Ayadi M, Kirzin S, Chazal M, Fléjou J-F, Benchimol D, Berger A, Lagarde A, Pencreach E, Piard F, Elias D, Parc Y, Olschwang S, Milano G, Laurent-Puig P, Boige V. Gene Expression Classification of Colon Cancer into Molecular Subtypes: Characterization, Validation, and Prognostic Value. PLoS Med. Kemp C. 2013 May 2110:e1001453.

9. Dienstmann R, Guinney J, Delorenzi M, de Reyniès A, Roepman P, Sadanandam A, Vermeulen L, Schlicker A, Missiaglia E, Soneson C, Marisa L, Homicsko K, Wang X, Simon I, Laurent-Puig P, Wessels LFA, Medema JP, Kopetz S, Friend SH, Tejpar S. Colorectal Cancer Subtyping Consortium. Colorectal Cancer Subtyping Consortium (CRCSC) identification of a consensus of molecular subtypes. ASCO Meeting Abstracts. 2014 Jun 11;32:3511.

10. Perez-Villamil B, Romera-Lopez A, Hernandez-Prieto S, Lopez-Campos G, Calles A, Lopez-Asenjo J-A, SanzOrtega J, Fernandez-Perez C, Sastre J, Alfonso R, Caldes T, Martin-Sanchez F, Diaz-Rubio E. Colon cancer molecular subtypes identified by expression profiling and associated to stroma, mucinous type and different clinical behavior. BMC Cancer. 2012; 12:260.

11. García-Bilbao A, Armañanzas R, Ispizua Z, Calvo B, Alonso-Varona A, Inza I, Larrañaga P, López-Vivanco G, Suárez-Merino B, Betanzos M. Identification of a biomarker panel for colorectal cancer diagnosis. BMC Cancer. BioMed Central Ltd. 2012 Jan 26;12:43.

12. deLeeuw RJ, Kost SE, Kakal JA, Nelson BH. The Prognostic Value of FoxP3+ Tumor-Infiltrating Lymphocytes in Cancer: A Critical Review of the Literature. Clinical Cancer Research. 2012 May 31;18:3022-9.

13. Ladoire S, Martin F, Ghiringhelli F. Prognostic role of FOXP3 + regulatory $\mathrm{T}$ cells infiltrating human carcinomas: the paradox of colorectal cancer. Cancer Immunol Immunother. 2011 Jun 5;60:909-18.

14. Pagès F, Berger A, Camus M, Sanchez-Cabo F, Costes A, Molidor R, Mlecnik B, Kirilovsky A, Nilsson M, Damotte D, Meatchi T, Bruneval P, Cugnenc P-H, Trajanoski Z, Fridman W-H, Galon J. Effector Memory $\mathrm{T}$ Cells, Early Metastasis, and Survival in Colorectal Cancer. N Engl J Med. 2005 Dec 22;353:2654-66.

15. Deschoolmeester V, Baay M, Van Marck E, Weyler J, Vermeulen P, Lardon F, Vermorken JB. Tumor infiltrating 
lymphocytes: an intriguing player in the survival of colorectal cancer patients. BMC Immunol. 2010;11:19.

16. Brown JR, DuBois RN. COX-2: a molecular target for colorectal cancer prevention. Clin Cancer Res. 2005 Apr 20;23:2840-55.

17. Burn J, Gerdes A-M, Macrae F, Mecklin J-P, Moeslein G, Olschwang S, Eccles D, Evans DG, Maher ER, Bertario L, Bisgaard M-L, Dunlop MG, Ho JWC, Hodgson SV, Lindblom A, Lubinski J, Morrison PJ, Murday V, Ramesar R, Side L, Scott RJ, Thomas HJW, Vasen HF, Barker G, Crawford G, Elliott F, Movahedi M, Pylvanainen K, Wijnen JT, Fodde R, Lynch HT, Mathers JC, Bishop DT. CAPP2 Investigators. Longterm effect of aspirin on cancer risk in carriers of hereditary colorectal cancer: an analysis from the CAPP2 randomised controlled trial. Lancet. 2011 Dec 17;378:2081-7.

18. Todaro M, Francipane MG, Medema JP, Stassi G. Colon cancer stem cells: promise of targeted therapy. Gastroenterology. 2010. pp. 2151-62.

19. Dalerba P, Dylla SJ, Park I-K, Liu R, Wang X, Cho RW, Hoey T, Gurney A, Huang EH, Simeone DM, Shelton AA, Parmiani G, Castelli C, Clarke MF. Phenotypic characterization of human colorectal cancer stem cells. Proc Natl Acad Sci USA. 2007 Jun 12;104:10158-63.

20. Barker N, van Es JH, Kuipers J, Kujala P, van den Born M, Cozijnsen M, Haegebarth A, Korving J, Begthel H, Peters PJ, Clevers H. Identification of stem cells in small intestine and colon by marker gene Lgr5. Nature. 2007 Oct 25;449:1003-7.

21. Sarkar A, Hochedlinger K. The sox family of transcription factors: versatile regulators of stem and progenitor cell fate. Cell Stem Cell. 2013 Jan 3;12:15-30.

22. Fong YW, Inouye C, Yamaguchi T, Cattoglio C, Grubisic I, Tjian R. A DNA repair complex functions as an Oct4/ Sox2 coactivator in embryonic stem cells. Cell. 2011 Sep 30;147:120-31.

23. Cancer Research UK. UK Cancer Incidence (2013). 2013; Apr 22:1-1.
24. Melchor L, Honrado E, García MJ, Álvarez S, Palacios J, Osorio A, Nathanson KL, Benítez J. Distinct genomic aberration patterns are found in familial breast cancer associated with different immunohistochemical subtypes. Oncogene. 2007 Dec 10;27:3165-75.

25. Roth AD, Delorenzi M, Tejpar S, Yan P, Klingbiel D, Fiocca R, d'Ario G, Cisar L, Labianca R, Cunningham D, Nordlinger B, Bosman F, Van Cutsem E. Integrated Analysis of Molecular and Clinical Prognostic Factors in Stage II/III Colon Cancer. JNCI Journal of the National Cancer Institute. 2012 Nov 6;104:1635-46.

26. Ong CW, Kim LG, Kong HH, Low LY, Iacopetta B, Soong R, Salto-Tellez M. CD133 expression predicts for non-response to chemotherapy in colorectal cancer. Mod Pathol. 2010 Mar 23:450-7.

27. Dunne PD, McArt DG, Blayney JK, Kalimutho M, Greer S, Wang T, Srivastava S, Ong CW, Arthur K, Loughrey M, Redmond K, Longley DB, Salto-Tellez M, Johnston PG, Van Schaeybroeck S. AXL is a key regulator of inherent and chemotherapy-induced invasion and predicts a poor clinical outcome in early-stage colon cancer. Clin Cancer Res. 2014 Jan 1;20:164-75.

28. Chan JY, Ong CW, Salto-Tellez M. Overexpression of neurone glial-related cell adhesion molecule is an independent predictor of poor prognosis in advanced colorectal cancer. Cancer Science. 2011 Oct;102:1855-61.

29. Tan HT, Wu W, Ng YZ, Zhang X, Yan B, Ong CW, Tan S, Salto-Tellez M, Hooi SC, Chung MCM. Proteomic analysis of colorectal cancer metastasis: stathmin-1 revealed as a player in cancer cell migration and prognostic marker. J Proteome Res. 2012 Feb 3;11:1433-45.

30. Gaujoux R, Seoighe C. A flexible R package for nonnegative matrix factorization. BMC Bioinformatics. 2010;11:367.

31. R Core Team. R: A language and environment for statistical computing. R Foundation for Statistical Computing, Vienna, Austria. 2013. 